\title{
Pelvic floor muscle exercise with biofeedback helps regain urinary continence after robot-assisted radical prostatectomy
}

\author{
Yeong Uk Kim ${ }^{1}$, Dong Gyu Lee ${ }^{2}$, Young Hwii Ko ${ }^{3}$ \\ ${ }^{1}$ Department of Urology, Yeungnam Hospital, of Medicine, Daegu, Korea \\ ${ }^{2}$ Department of Physical Medicine and Rehabilitation, Yeungnam University College of Medicine, Daegu, Korea \\ ${ }^{3}$ Department of Urology, Yeungnam University College of Medicine, Daegu, Korea
}

Received: April 12, 2020

Revised: May 5, 2020

Accepted: May 7, 2020

Corresponding author:

Young Hwii Ko

Department of Urology, Yeungnam

University College of Medicine, 170

Hyeonchung-ro, Namgu, Daegu

42415, Korea

Tel: +82-53-620-3694

Fax: +82-53-627-5535

E-mail:urokyh@naver.com
Background: To determine the benefit of pelvic floor muscle exercise (PFME) with visual biofeedback on promoting patient recovery from incontinence, we investigated variables associated with the early restoration of continence for patients who underwent robot-assisted radical prostatectomy (RARP).

Methods: Of the 83 patients enrolled, 41 consecutive patients completed PFME (the exercise group), and the other 42 consecutive patients just before the PFME program commenced (the control group). The primary outcome was whether PFME engagement was associated with zero pad continence restoration within 3 months of surgery.

Results: Continence restoration percentages (defined as zero pads used per day) at 1, 3, and 6 months after surgery were $49.4 \%, 77.1 \%$, and $94.0 \%$, respectively. The exercise group achieved significantly higher recovery rates at 1 month $(p=0.037), 3$ months $(p<0.001)$, and 6 months $(p=023)$. Cox regression analysis demonstrated that a lower Gleason score $(<8$; hazard ratio $[H R], 2.167)$, lower prostate specific antigen ( $<20 \mathrm{ng} / \mathrm{dL} ; \mathrm{HR}, 2.909)$, and engagement in PFME $(H R, 3.731)$ were independent predictors of early recovery from postprostatectomy incontinence. Stratification by age showed that those younger than 65 years did not benefit significantly from exercise (log-rank test, $p=0.08)$, but that their elderly counterparts, aged 65-70 years ( $p=0.007)$ and $>70$ years old $(p=0.002)$ benefited significantly.

Conclusion: This study suggests that postoperative engagement in PFME with biofeedback speeds up the recovery of continence in elderly patients ( $\geq 65$ years old) that undergo RARP.

Keywords: Aged; Biofeedback; Prostatectomy; Urinary incontinence

\section{Introduction}

Radical prostatectomy $(\mathrm{RP})$ is a standard treatment for non-metastatic prostate cancer [1]. Increased enthusiasm for radical organ removal as a reliable treatment option for high-risk or locally advanced disease, combined with the minimal invasiveness unique to ro- bot-assisted radical prostatectomy (RARP), has resulted in RP becoming the contemporary treatment of choice. However, postprostatectomy incontinence (PPI) remains a serious issue that diminishes postoperative quality of life [2]. The majority of patients experience urinary incontinence immediately after $\mathrm{RP}$, and in some cases this incontinence is protracted. As such, urinary incontinence is a

Copyright (C) 2021 Yeungnam University College of Medicine

This is an Open Access article distributed under the terms of the Creative Commons Attribution Non-Commercial License (http://creativecommons.org/licenses/by-nc/4.0/) which permits unrestricted non-commercial use, distribution, and reproduction in any medium, provided the original work is properly cited. 
major source of concern for patients requiring RP or RARP.

As a postoperative intervention, pelvic floor muscle exercise (PFME), with or without biofeedback, is known to promote muscle contraction and hasten recovery from PPI. Although initial trials produced promising results, systematic reviews have led to questions regarding the efficacy of PFME [3]. Furthermore, no large-scale randomized controlled trials (RCTs) have been conducted to test the efficacy of PFME with biofeedback, although a trial is underway [4]. In addition, published evidence regarding the efficacy of existing PFME programs for preventing and treating PPI is inconsistent [5].

In an attempt to identify factors that hasten the restoration of continence, we compared outcomes between patients who engaged in PFME with visual biofeedback and patients who engaged in the Kegel exercise with verbal instructions alone. Given uncertainties regarding the benefits of PFME, we minimized confounding factors by using data from patients treated by a single surgeon, using the same RARP technique over a period of 1 year.

\section{Material and methods}

\section{Recruitment of the exercise and study groups}

This study was approved by the Institutional Review Board of the Yeungnam University Hospital (IRB No: 2020-05-001).

All patients that underwent RARP, performed by a single experienced surgeon (YHK) from September 2018 to August 2019, were enrolled in this study. During RARP three procedures were performed: unilateral, bilateral, or no nerve-sparing; bladder neck preservation; and posterior reconstruction. The same surgical techniques were used throughout the 12-month study period. The study exclusion criteria were as follows: previous pelvic radiation therapy, poor compliance due to psychiatric or medical problems, previous prostate surgery, and $<3$ months of follow-up after surgery. Of the 94 patients initially considered, two men that required a cardiac procedure after RARP and nine that were followed for $<3$ months were excluded. Accordingly, 83 participants constituted the study cohort. Forty-one of the 83 participants (49.4\%) engaged in PFME with biofeedback (the exercise group), while the other 42 did not (the control group), as they underwent RARP using the same technique just before the PFME program was adopted.

In the exercise group, PFME with biofeedback was performed by a single physiotherapist (DGL) on patients that underwent RARP between March 2019 and August 2019. Patients in the control group underwent RARP between September 2018 and February 2019 and performed the Kegel exercise at home after being given oral instructions by a urologist (YHK).

\section{Pelvic floor muscle exercise}

Patients in the exercise group began engaging in PFME immediately after Foley catheter removal, which was routinely performed 5 days after RARP. Patients received PFME with biofeedback on an outpatient basis for 30 minutes per week until continence was regained or 4 weeks had elapsed. Ultrasonography was used to visualize pelvic floor muscle contractions. Patients were asked to perform 20-25 contractions with durations from 3-5 seconds at submaximal strength in the lateral decubitus, supine (with hips flexed at $60^{\circ}$ ), and standing positions. A relaxation period of 6-10 seconds was allowed between contractions. The physiotherapist checked pelvic floor muscles by palpating the perineum, examined contractions via ultrasonography in each position, and showed patients how to contract pelvic floor muscles correctly on avoiding Valsalva maneuver. In addition, patients were asked to repeat the exercise at home. Patients in the control group were given verbal instructions on the Kegel exercise by a single urologist and asked to perform 50-100 exercises daily at home while lying, sitting, and standing.

\section{Outcome assessments}

Postoperatively, all 83 patients were routinely followed-up in an outpatient office at 1 week and 1, 3, and 6 months after surgery. During each visit, patients were asked about daily pad use and the last date of pad usage. Continence in this study was strictly defined as the cessation of pad use, regardless of the type of pad used. The primary outcome of this study was the determination of whether PFME with biofeedback impacts the restoration of continence within the 3 months following RARP.

\section{Statistical analysis}

Group clinicopathological characteristics were compared using Student $t$-test for continuous variables and a chi-squared test for categorical variables. Given the well-documented association between time and recovery from PPI, the Cox proportional hazards model was used to identify predictors of early continence restoration. The Kaplan-Meier method with the log-rank test was used to compare groups with respect to time to continence. Data were analyzed using IBM SPSS version 19.0 (IBM Corp., Armonk, NY, USA). All tests were two-sided and $p$-values $<0.05$ were considered statistically significant.

\section{Results}

\section{Participant characteristics}

The characteristics of patients in the exercise (PFME with biofeedback) and the control (conventional Kegel exercise) groups 
are summarized in Table 1. Continuous and categorical variables were similar in the two groups, except initial serum prostate specific antigen (PSA) levels, which were significantly higher in the exercise group $(p=0.025)$. However, the proportions of patients with a PSA value $\geq 20 \mathrm{ng} / \mathrm{dL}$ (the cut-off for high-risk disease) was similar $(p=0.276)$ across groups. The proportion of patients with a Gleason score $>8$ was marginally higher in the exercise group $(p=0.09)$.

\section{Continence outcomes and variables associated with early continence restoration}

Continence restoration rates for all study subjects at 1 week, and 1,3 , and 6 months after surgery were $18.1 \%, 49.4 \%, 77.1 \%$, and $94.0 \%$, respectively. The exercise group had higher rates of continence restoration than controls at 1 month $(p=0.037), 3$ months $(p<0.001)$, and 6 months $(p=0.023)$ (Table 2). Three months after surgery, all 41 patients in the exercise group had regained continence. Furthermore, the mean time to restored continence was significantly shorter in the exercise group (32.4 vs. 95.3 days, $p<0.001$ ) (Fig. 1). Other than the implementation of PFME instructions, no factors differed between participants who had or had not regained continence after 3 months (Table 3 ).

\section{Multivariate analysis of early continence restoration and post-hoc analysis by age}

Cox proportional hazards analysis demonstrated that a lower Gleason score (<8; hazard ratio [HR], 2.167), a lower initial PSA $(<20$ ng/dL; HR, 2.909), and PFME completion (HR, 3.731) were associated with continence restoration within 3 months of RARP (Table 4). After stratifying all study subjects by age, those aged $<65$

Table 1. Characteristics of the patients enrolled

\begin{tabular}{|c|c|c|c|c|}
\hline & $\begin{array}{l}\text { PFME with biofeedback group } \\
\qquad(\mathrm{n}=41,49.4 \%)\end{array}$ & $\begin{array}{l}\text { Conventional Kegel exercise group } \\
\qquad(n=42,50.6 \%)\end{array}$ & $\begin{array}{c}\text { Total } \\
(n=83)\end{array}$ & $p$-value \\
\hline Age $(\mathrm{yr})$ & $68.4 \pm 5.98$ & $67.7 \pm 4.90$ & $68.1 \pm 5.44$ & 0.561 \\
\hline$<65$ & $12(29.3)$ & $13(31.0)$ & 25 & 0.952 \\
\hline $65-70$ & $16(39.0)$ & $17(40.5)$ & 33 & \\
\hline$>70$ & 13 (31.7) & $12(28.5)$ & 25 & \\
\hline \multicolumn{5}{|l|}{ Diabetes mellitus } \\
\hline No & 37 (90.2) & 34 (81.0) & 71 & 0.229 \\
\hline Yes & $4(9.8)$ & $8(19.0)$ & 12 & \\
\hline \multicolumn{5}{|l|}{ Coronary heart disease } \\
\hline No & 36 (87.8) & $40(95.2)$ & 76 & 0.223 \\
\hline Yes & $5(12.2)$ & $2(4.8)$ & 7 & \\
\hline \multicolumn{5}{|l|}{ Gleason score } \\
\hline$<8$ & $23(56.1)$ & $31(73.8)$ & 54 & 0.091 \\
\hline$\geq 8$ & $18(43.9)$ & $11(26.2)$ & 29 & \\
\hline Prostate volume (gm) & $33.8 \pm 15.2$ & $36.2 \pm 13.8$ & $35.0 \pm 14.5$ & 0.448 \\
\hline$<40$ & $31(75.6)$ & $27(64.3)$ & 58 & 0.261 \\
\hline$\geq 40$ & $10(24.4)$ & $15(35.7)$ & 25 & \\
\hline Initial PSA (ng/dL) & $45.4 \pm 78.7$ & $16.8 \pm 20.5$ & $30.9 \pm 58.6$ & 0.025 \\
\hline$<20$ & $29(70.7)$ & $34(81.0)$ & 63 & 0.276 \\
\hline$\geq 20$ & $12(29.3)$ & $8(19.0)$ & 20 & \\
\hline \multicolumn{5}{|l|}{ Pathological T stage } \\
\hline$\leq \mathrm{pT} 2$ & $19(46.3)$ & $24(57.1)$ & 43 & 0.325 \\
\hline$\geq \mathrm{pT} 3$ & $22(53.7)$ & $18(42.9)$ & 40 & \\
\hline \multicolumn{5}{|c|}{ Nerve-sparing procedure } \\
\hline Non-NS & $33(80.5)$ & 35 (83.3) & 68 & 0.736 \\
\hline NS RARP & $8(19.5)$ & $7(16.7)$ & 15 & \\
\hline \multicolumn{5}{|l|}{ Adjuvant radiation } \\
\hline No RT & 39 (95.1) & $40(95.2)$ & 79 & 0.98 \\
\hline Adjuvant RT & $2(4.9)$ & $2(4.8)$ & 4 & \\
\hline
\end{tabular}

Values presented as mean \pm standard deviation or number (\%).

PFME, pelvic floor muscle exercise; PSA, prostate specific antigen; NS, nerve-sparing; RARP, robot-assisted radical prostatectomy; RT, radiation therapy. 
Table 2. Continence outcome between PFME with biofeedback and conventional Kegel exercise groups

\begin{tabular}{|c|c|c|c|c|}
\hline & $\begin{array}{l}\text { PFME with biofeedback group } \\
\qquad(n=41,49.4 \%)\end{array}$ & $\begin{array}{l}\text { Conventional Kegel exercise group } \\
\qquad(n=42,50.6 \%)\end{array}$ & $\begin{array}{c}\text { Total } \\
(n=83)\end{array}$ & $p$-value \\
\hline Pad period (day) & $32.4 \pm 30.3$ & $95.3 \pm 98.5$ & $64.2 \pm 79.4$ & $<0.001$ \\
\hline \multicolumn{5}{|c|}{ Continence regain within $1 \mathrm{wk}$} \\
\hline Zero pad & $9(22.0)$ & $6(14.3)$ & $15(18.1)$ & \multirow[t]{2}{*}{0.364} \\
\hline Incontinence & $32(78.0)$ & $36(85.7)$ & $68(81.9)$ & \\
\hline \multicolumn{5}{|c|}{ Continence regain within 1 mo } \\
\hline Zero pad & $25(61.0)$ & $16(38.1)$ & $41(49.4)$ & \multirow[t]{2}{*}{0.037} \\
\hline Incontinence & $16(39.0)$ & $26(61.9)$ & $42(50.6)$ & \\
\hline \multicolumn{5}{|c|}{ Continence regain within 3 mo } \\
\hline Zero pad & $41(100)$ & $23(54.8)$ & $64(77.1)$ & \multirow[t]{2}{*}{$<0.001$} \\
\hline Incontinence & 0 & $19(45.2)$ & $19(22.9)$ & \\
\hline \multicolumn{5}{|c|}{ Continence regain within 6 mo } \\
\hline Zero pad & $41(100)$ & $37(88.1)$ & $78(94.0)$ & \multirow[t]{2}{*}{0.023} \\
\hline Incontinence & 0 & $5(11.9)$ & $5(6.0)$ & \\
\hline
\end{tabular}

Values presented as mean \pm standard deviation or number (\%).

PFME, pelvic floor muscle exercise.

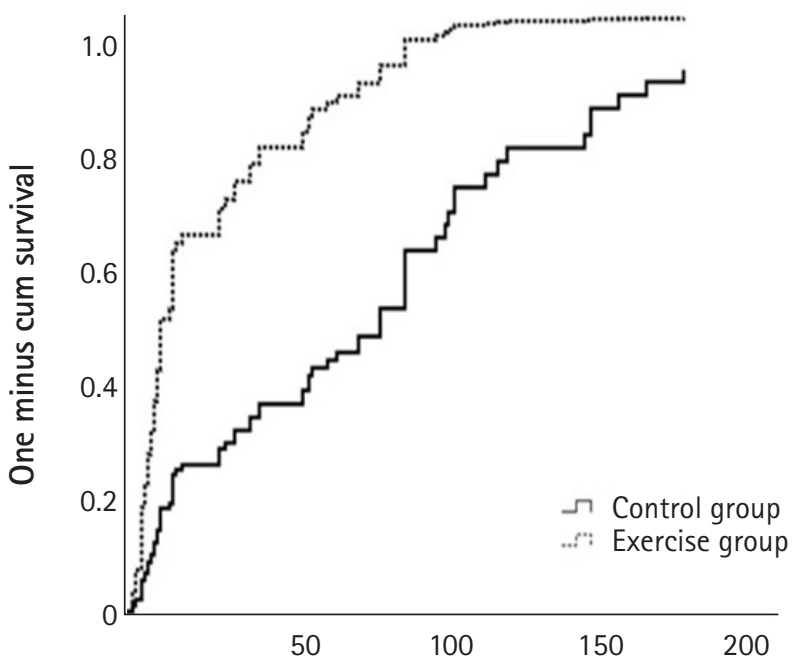

Pad period (day)

Fig. 1. Time to urinary incontinence in all patients (log-rank test $p<0.001)$.

years were found to receive no significant benefit from exercise (logrank test, $p=0.08$ ) (Fig. 2A). In contrast, patients ranging from 6570 years of age $(p=0.007)$ (Fig. $2 \mathrm{~B})$ and those older than 70 years $(p=0.002)$ (Fig. 2C) benefited significantly from PFME.

\section{Discussion}

The incidence of PPI has been reported to range from as low as $2 \%$ to as high as $87 \%$ with significant leakage in $0.3 \%-12.5 \%$ of patients at 1 month after surgery [6]. Furthermore, PPI has been reported to last as long as 1-2 years after surgery [7].

The physiological mechanism underlying PPI is multifactorial and has been attributed, in part, to damage to the sphincter. This structure is composed of smooth inner muscles and the rhabdo-sphincter muscle [8-10]. PPI also compromises a supporting system, including Denonvilliers' fascia, the puboprostatic ligament, the endopelvic fascia, and the levator ani muscle, during RP [11]. Based on these mechanisms, many intraoperative interventions have been devised to reduce the severity and incidence of PPI. These include bladder neck preservation, posterior reconstruction, and a nerve-sparing procedure [12-14].

PFME with or without biofeedback is a type of postoperative intervention that improves urinary continence after RP. According to the European Association of Urology guidelines, PFME with or without biofeedback is the recommended option for conservative management of PPI [15]. Theoretically, PFME improves sphincter function by enhancing rhabdosphincter tone and strengthening levator ani muscles [16]. Several studies have reported on the short- and long-term effects of PFME with biofeedback. Ribeiro et al. [17] conducted an RCT of 73 patients and demonstrated that early PFME with biofeedback after RARP was superior to conventional PFME, as measured by the continence recovery rate at 1 year after surgery ( $96 \%$ vs. $75 \% ; p=0.028)$. Burgio et al. [18] suggested that preoperative behavioral training can reduce time to recovery of urine control and reduce the severity of incontinence after RP. On the other hand, Bales et al. [19] reported that continence restoration at 1,2,3, and 4 months after surgery was not significantly different between biofeedback and control groups. Overgard et al. [20] carried out an RCT of 85 pa- 
Table 3. Comparison of the patient who obtained continence within 3 months after surgery or not

\begin{tabular}{|c|c|c|c|c|}
\hline \multirow{2}{*}{ Variable } & \multicolumn{2}{|c|}{ Continence within $3 \mathrm{mo}$} & \multirow{2}{*}{ Total $(n=83)$} & \multirow{2}{*}{$p$-value } \\
\hline & Continence $(n=64,77.1 \%)$ & Incontinence $(n=19,22.9 \%)$ & & \\
\hline Age (yr) & $68.0 \pm 5.45$ & $68.3 \pm 5.53$ & $68.1 \pm 5.44$ & 0.854 \\
\hline$<65$ & $20(31.3)$ & $5(26.4)$ & 25 & 0.763 \\
\hline $65-70$ & $26(40.6)$ & $7(36.8)$ & 33 & \\
\hline$>70$ & $18(28.1)$ & $7(36.8)$ & 25 & \\
\hline \multicolumn{5}{|l|}{ Diabetes mellitus } \\
\hline No & $55(85.9)$ & $16(84.2)$ & 71 & 0.851 \\
\hline Yes & $9(14.1)$ & $3(15.8)$ & 12 & \\
\hline \multicolumn{5}{|l|}{ Coronary heart disease } \\
\hline No & $58(90.6)$ & 18 (94.7) & 76 & 0.571 \\
\hline Yes & $6(9.4)$ & $1(5.3)$ & 7 & \\
\hline \multicolumn{5}{|l|}{ Gleason score } \\
\hline$<8$ & $41(64.1)$ & $13(68.4)$ & 54 & 0.726 \\
\hline$\geq 8$ & $23(35.9)$ & $6(31.6)$ & 29 & \\
\hline Prostate volume (gm) & $34.0 \pm 15.1$ & $38.5 \pm 12.3$ & $35.0 \pm 14.5$ & 0.234 \\
\hline$<40$ & $47(73.4)$ & $11(57.9)$ & 58 & 0.195 \\
\hline$\geq 40$ & $17(26.6)$ & $8(42.1)$ & 25 & \\
\hline Initial PSA (ng/dL) & $33.2 \pm 65.1$ & $23.5 \pm 27.9$ & $30.9 \pm 58.6$ & 0.529 \\
\hline$<20$ & $50(78.1)$ & $13(68.4)$ & 63 & 0.385 \\
\hline$\geq 20$ & $14(21.9)$ & $6(31.6)$ & 20 & \\
\hline \multicolumn{5}{|l|}{ Pathological T stage } \\
\hline$\leq \mathrm{pT} 2$ & $30(46.9)$ & $13(68.4)$ & 43 & 0.099 \\
\hline$\geq \mathrm{pT} 3$ & $34(53.1)$ & $6(31.6)$ & 40 & \\
\hline \multicolumn{5}{|l|}{ Nerve-sparing procedure } \\
\hline Non-NS & $54(84.4)$ & 14 (73.7) & 68 & 0.288 \\
\hline NS RARP & $10(15.6)$ & $5(26.3)$ & 15 & \\
\hline \multicolumn{5}{|l|}{ Adjuvant radiation } \\
\hline No RT & $61(95.3)$ & 18 (94.7) & 79 & 0.918 \\
\hline Adjuvant RT & $3(4.7)$ & $1(5.3)$ & 4 & \\
\hline \multicolumn{5}{|l|}{ PFME with biofeedback } \\
\hline No & $23(35.9)$ & 19 (100.0) & 42 & $<0.001$ \\
\hline Yes & $41(64.1)$ & $0(0.0)$ & 41 & \\
\hline
\end{tabular}

Values presented as mean \pm standard deviation or number (\%).

PSA, prostate specific antigen; NS, nerve-sparing; RARP, robot-assisted radical prostatectomy; RT, radiation therapy; PFME, pelvic floor muscle exercise.

tients and found that early continence restoration rates were similar in a PFME with biofeedback group and in a control group ( $46 \%$ vs. $43 \%, p=0.73$ ). Therefore, the efficacy of perioperative PFME with biofeedback remains a controversial topic.

We defined continence as the cessation of daily pad use. Several studies defined continence as the use of a single safety or 0 pads daily $[17,20]$, whereas others defined it based on 1 hour or 24 hours pad test results, as recommended by the International Continence Society [21]. We believe that defining continence based on pad usage is sufficient for the assessment of continence and more convenient for patients than the pad test.

Unfortunately, in some studies of the efficacy of PFME after
$\mathrm{RP}$, many factors that might predispose patients to PPI, such as type of surgery or number of surgeons, were not controlled. In a study by Geraerts et al. [22], RP was performed by open surgery or RARP and patient numbers between these two groups were unequal (open $=116$ vs. $\mathrm{RARP}=54$ ), and in a multicenter study by Floratos et al. [23], radical prostatectomies were conducted by any of four experienced surgeons. These factors can lead to statistical errors when assessing the efficacy of PFME for PPI. On the other hand, the present study was conducted at a single institute by a surgeon who had experience with more than 200 cases.

Additionally, we investigated the independent factors including PFME with biofeedback for early continence restoration, based 
Table 4. Cox-continence regain within 3 months

\begin{tabular}{lcc}
\hline Variable (reference value) & $p$-value & OR (95\% Cl) \\
\hline Age $(<65 \mathrm{yr})$ & 0.149 & $1.535(0.857-2.749)$ \\
Diabetes mellitus (no) & 0.165 & $1.753(0.793-3.873)$ \\
Coronary heart disease (no) & 0.952 & $0.968(0.338-2.773)$ \\
Gleason score $(<8)$ & 0.040 & $2.167(1.035-4.539)$ \\
Prostate volume $(<40 \mathrm{gm})$ & 0.342 & $0.743(0.403-1.371)$ \\
Initial PSA (<20 ng/dL) & 0.018 & $2.909(1.197-7.072)$ \\
Pathological T stage ( $\leq \mathrm{pT2})$ & 0.917 & $0.965(0.497-1.876)$ \\
Nerve-sparing (yes) & 0.573 & $0.760(0.292-1.977)$ \\
Adjuvant radiation (no) & 0.735 & $0.798(0.217-2.941)$ \\
PFME (yes) & $<0.001$ & $3.731(2.081-6.690)$
\end{tabular}

$\mathrm{OR}$, odds ratio; $\mathrm{Cl}$, confidence interval; $\mathrm{PSA}$, prostate specific antigen; $\mathrm{PFME}$, pelvic floor muscle exercise.

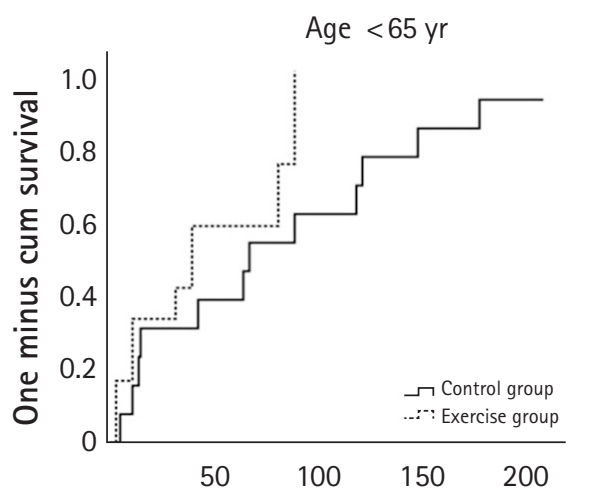

A

Pad period (day)
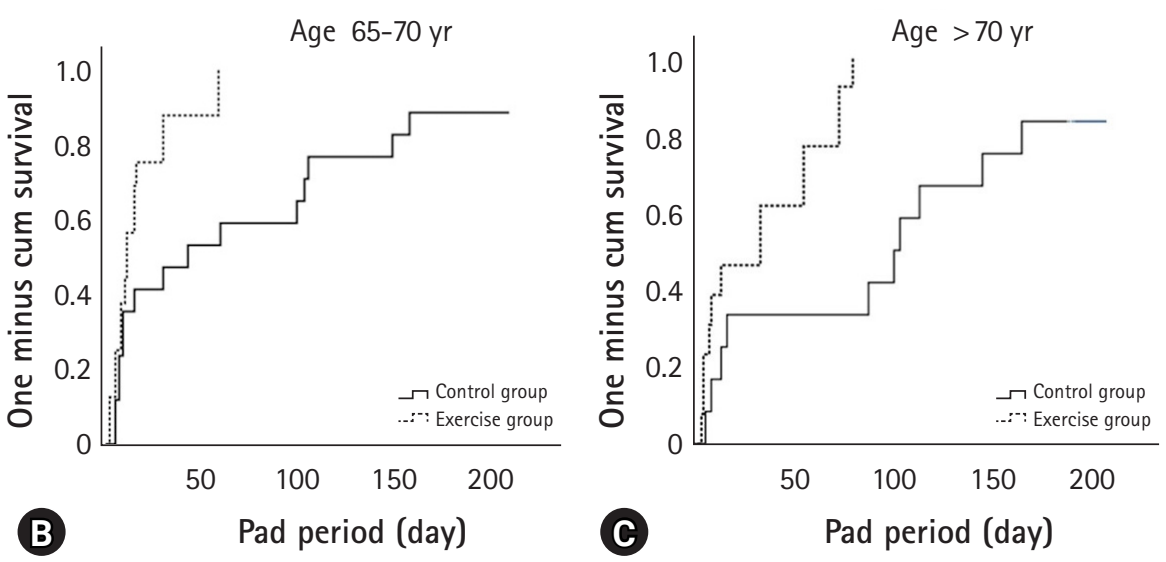

Fig. 2. (A) Time to urinary incontinence in men under 65 years of age (log-rank test $p=0.08)$. (B) Time to urinary incontinence in men between 65 to 70 years of age (log-rank test $p=0.007)$. (C) Time to urinary incontinence in men over 70 years of age (log-rank test $p=0.002)$.

on the days of pads used. In the majority of previous studies on the effectiveness of PFME with biofeedback, predictive factors, such as age, receipt of a nerve-sparing procedure, and type of surgery, were not considered. We believe that it will be statistically persuasive to establish the relationship between early continence restoration and other clinic-pathological factors for PPI, including PFME with biofeedback, because these factors could also affect PPI recovery rates.

In our study, PFME with biofeedback had a more positive impact on PPI in elderly men ( $>70$ years old) than in younger men. In a systematic review of factors that contribute to PPI, age was found to have a negative impact on continence rate after RP [24]. Simard and $\mathrm{Tu}$ [25] reported that pelvic floor muscle rehabilitation with physiotherapy was effective in elderly women with urinary incontinence. However, no study has addressed the relationship between age and the efficacy of PFME with biofeedback. Based on the results of this study, we suggest that PFME with bio- feedback for patients with PPI is more effective in elderly men.

The present study has a number of limitations that deserve consideration. First, the number of patients enrolled was relatively small and the study was inherently limited by its retrospective design. However, by adopting data derived from a single surgeon's experience, we sought to minimize the influence of potential covariates. Second, we focused on early recovery, and did not investigate the long-term effects of PFME with biofeedback, because experience has shown that the benefits of PFME with biofeedback manifest during the earlier stages of recovery. Third, self-questionnaires, such as the International Prostate Symptom Score or International Consultation on Incontinence Questionnaire, were not used, although the majority of recent studies have used self-questionnaires to determine outcomes. Therefore, we suggest that further larger-scale studies be conducted to assess the efficacy of PFME with biofeedback, especially in elderly men.

In conclusion, PFME with visual biofeedback was found to be 
an effective intervention for promoting early continence restoration (within 3 months) in patients that suffered from urinary incontinence after RARP. Furthermore, this study showed that PFME with biofeedback more effectively results in early continence restoration, after RARP, in elderly men.

\section{Acknowledgments}

\section{Conflicts of interest}

No potential conflict of interest relevant to this article was reported.

\section{Author contributions}

Conceptualization: all authors; Formal analysis: YUK; Methodology: DGL; Project administration, Supervision: YHK; Investigation: YUK; Writing-original draft: YUK; Writing-review \& editing: YHK.

\section{ORCID}

Yeong Uk Kim, https://orcid.org/0000-0002-8783-9567

Dong Gyu Lee, https://orcid.org/0000-0002-4787-4448

Young Hwii Ko, https://orcid.org/0000-0002-9150-4292

\section{References}

1. Yossepowitch O, Eggener SE, Bianco FJ Jr, Carver BS, Serio A, Scardino PT, et al. Radical prostatectomy for clinically localized, high risk prostate cancer: critical analysis of risk assessment methods.J Urol 2007;178:493-9.

2. Ficarra V, Novara G, Rosen RC, Artibani W, Carroll PR, Costello A, et al. Systematic review and meta-analysis of studies reporting urinary continence recovery after robot-assisted radical prostatectomy. Eur Urol 2012;62:405-17.

3. Chang JI, Lam V, Patel MI. Preoperative pelvic floor muscle exercise and postprostatectomy incontinence: a systematic review and meta-analysis. Eur Urol 2016;69:460-7.

4. Averbeck MA, Marcelissen T, Anding R, Rahnama'i MS, Sahai A, Tubaro A. How can we prevent postprostatectomy urinary incontinence by patient selection, and by preoperative, peroperative, and postoperative measures? International Consultation on Incontinence-Research Society 2018. Neurourol Urodyn 2019;38:119-26.

5. Hodges PW, Stafford RE, Hall L, Neumann P, Morrison S, Frawley $\mathrm{H}$. Reconsideration of pelvic floor muscle training to prevent and treat incontinence after radical prostatectomy. Urol Oncol 2019;24:1-18.

6. Jonler M, Madsen FA, Rhodes PR, Sall M, Messing EM,
Bruskewitz RC. A prospective study of quantification of urinary incontinence and quality of life in patients undergoing radical retropubic prostatectomy. Urology 1996;48:433-40.

7. Sanda MG, Dunn RL, Michalski J, Sandler HM, Northouse L, Hembroff $L$, et al. Quality of life and satisfaction with outcome among prostate cancer-survivors. N Engl J Med 2008;358: 1250-61.

8. Chao R, Mayo ME. Incontinence after radical prostatectomy: detrusor or sphincter causes. J Urol 1995;154:16-8.

9. Desautel MG, Kapoor R, Badlani GH. Sphincteric incontinence: the primary cause of post-prostatectomy incontinence in patients with prostate cancer. Neurourol Urodyn 1997;16:15360.

10. Ficazzola MA, Nitti VW. The etiology of post-radical prostatectomy incontinence and correlation of symptoms with urodynamic findings. J Urol 1998;160:1317-20.

11. Kojima Y, Takahashi N, Haga N, Nomiya M, Yanagida T, Ishibashi $\mathrm{K}$, et al. Urinary incontinence after robot-assisted radical prostatectomy: pathophysiology and intraoperative techniques to improve surgical outcome. Int J Urol 2013;20:105263.

12. Srivastava A, Chopra S, Pham A, Sooriakumaran P, Durand M, Chughtai B, et al. Effect of a risk-stratified grade of nerve-sparing technique on early return of continence after robot-assisted laparoscopic radical prostatectomy. Eur Urol 2013;63:438-44.

13. Freire MP, Weinberg AC, Lei Y, Soukup JR, Lipsitz SR, Prasad SM, et al. Anatomic bladder neck preservation during robotic-assisted laparoscopic radical prostatectomy: description of technique and outcomes. Eur Urol 2009;56:972-80.

14. Rocco F, Carmignani L, Acquati P, Gadda F, Dell'Orto P, Rocco B, et al. Early continence recovery after open radical prostatectomy with restoration of the posterior aspect of the rhabdosphincter. Eur Urol 2007;52:376-83.

15. Mottet N, Bellmunt J, Bolla M, Briers E, Cumberbatch MG, De Santis M, et al. EAU-ESTRO-SIOG guidelines on prostate cancer. Part 1: screening, diagnosis, and local treatment with curative intent. Eur Urol 2017;71:618-29.

16. Anderson CA, Omar MI, Campbell SE, Hunter KF, Cody JD, Glazener CM, et al. Conservative management for postprostatectomy urinary incontinence. Cochrane Database Syst Rev 2015;1:CD001843.

17. Ribeiro LH, Prota C, Gomes CM, de Bessa J Jr, Boldarine MP, Dall'Oglio MF, et al. Long-term effect of early postoperative pelvic floor biofeedback on continence in men undergoing radical prostatectomy: a prospective, randomized, controlled trial. J Urol 2020;184:1034-9.

18. Burgio KL, Goode PS, Urban DA, Umlauf MG, Locher JL, 
Bueschen A, et al. Preoperative biofeedback assisted behavioral training to decrease post-prostatectomy incontinence: a randomized, controlled trial. J Urol 2006; 175:196-201.

19. Bales GT, Gerber GS, Minor TX, Mhoon DA, McFarland JM, Kim HL, et al. Effect of preoperative biofeedback/pelvic floor training on continence in men undergoing radical prostatectomy. Urology 2000;56:627-30.

20. Overgard M, Angelsen A, Lydersen S, Morkved S. Does physiotherapist-guided pelvic floor muscle training reduce urinary incontinence after radical prostatectomy? A randomized controlled trial. Eur Urol 2008;54:438-48.

21. Haylen BT, de Ridder D, Freeman RM, Swift SE, Berghmans B, Lee J, et al. An International Urogynecological Association (IUGA)/International Continence Society (ICS) joint report on the terminology for female pelvic floor dysfunction. Int Urogynecol J 2010;21:5-26.

22. Geraerts I, Van Poppel H, Devoogdt N, Joniau S, Van Cleynen- breugel B, De Groef A, et al. Influence of preoperative and postoperative pelvic floor muscle training (PFMT) compared with postoperative PFMT on urinary incontinence after radical prostatectomy: a randomized controlled trial. Eur Urol 2013; 64:766-72.

23. Floratos DL, Sonke GS, Rapidou CA, Alivizatos GJ, Deliveliotis C, Constantinides CA, et al. Biofeedback vs verbal feedback as learning tools for pelvic muscle exercises in the early management of urinary incontinence after radical prostatectomy. BJU Int 2002;89:714-9.

24. Heesakkers J, Farag F, Bauer RM, Sandhu J, De Ridder D, Stenzl A. Pathophysiology and contributing factors in postprostatectomy incontinence: a review. Eur Urol 2017;71:936-44.

25. Simard C, Tu LM. Long-term efficacy of pelvic floor muscle rehabilitation for older women with urinary incontinence. J Obstet Gynaecol Can 2010;32:1163-6. 